\title{
Benign Cystic Mesothelioma in a Child: Case Report and Review of the Literature
}

\author{
Ahmet Ali Tuncer ${ }^{1}$, Adnan Narci², Fatma Hüsniye Dilek ${ }^{3}$, Didem Baskın Embleton ${ }^{4}$, Salih Çetinkurşun ${ }^{4}$ \\ ${ }^{1}$ Department of Pediatric Surgery, Yüksekova State Hospital, Hakkari, Turkey \\ ${ }^{2}$ Department of Pediatric Surgery, Sifa University School of Medicine, İzmir, Turkey \\ ${ }^{3}$ Department of Pathology, Sakarya University Training and Research Hospital, Sakarya, Turkey \\ ${ }^{4}$ Department of Pediatric Surgery, Afyon Kocatepe University School of Medicine, Afyonkarahisar, Turkey
}

Background: Benign cystic mesothelioma (BCM) is a rare tumor with benign characteristic. There are only 8 child cases reported in the English literature. In this report, we present this rare entity a brief review of the literature.

Case Report: A two year-old boy presenting with abdominal swelling was hospitalized. Physical examination revealed a mass filling the abdomen. Laboratory findings were not specific. Abdominal computerized tomography showed a $15 \times 13 \times 11 \mathrm{~cm}$ cystic mass extending from the bladder to the liver with no solid components and no infiltration to adjacent organs. Operation revealed a cystic mass filled with yellow-green serous fluid which was attached to the right lobe of the liver with a $1 \mathrm{~cm}$ thick peduncle. Total excision of the mass was performed by clamping and cutting the narrow attachment. Recovery was uneventful. Pathology revealed multiple cysts lined with mesothelial cells. No recurrence was seen after 5 years of follow-up.

Conclusion: BCM should be kept in mind as a rare cause of the abdominal mass in children, as it may lead to confusion in preoperative diagnosis. Although rare, patients should be followed throughout life because of the risk of recurrence and malignant degeneration.

Keywords: Child, cysts, liver, mesothelioma, pediatric tumor
Benign cystic mesothelioma (BCM) is an uncommon tumor with benign characteristic. Since it was first described in 1979 , a total of 141 case reports have been published in the literature, including 8 children (1). In this article, a 2 year-old boy with BCM originating from the liver is presented, with a brief review of the literature.

\section{CASE PRESENTATION}

Written informed consent was obtained from the patient's parent who participated in this case.

A two year-old boy offered with massive abdominal swelling, abdominal pain and uneasiness was hospitalized. Physical examination revealed a mass filling the abdomen. Laboratory findings were not specific. Ultrasonography and abdominal contrast-enhanced computed tomography (CT) showed a $15 \times 13 \times 11 \mathrm{~cm}$ multicystic mass extending from the bladder to the liver with no solid components and no infiltration to adjacent organs (Figure 1). The patient was operated with a supraumbilical transverse incision. Operation revealed a cystic mass filled with yellow-green serous fluid which was attached to the right lobe of the liver with a $1 \mathrm{~cm}$ thick peduncle. Total excision of the mass was performed by clamping and cutting the narrow attachment (Figure 2). Recovery was uneventful. Immunohistochemical studies revealed multiple cysts lined by mesothelial cells and there was strong cytoplasmic immunoreactivity for calretinin (Calretinin (SP 13); Lab Vision Corporation, Fremont, USA) in cells lining the cysts (Figure 2).

This study was presented as a poster walk presentation at the $3^{\text {rd }}$ World Congress of Pediatric Surgery, 21-24 October 2010, New Delhi, India.

Address for Correspondence: Dr. Ahmet Ali Tuncer, Department of Pediatric Surgery, Yüksekova State Hospital, Hakkari, Turkey

Phone: +90 5059489371 e-mail: drtaali@yahoo.com

Received: 12 October 2014 Accepted: 12 May 2015 •DOI: 10.5152/balkanmedj.2015.15886

Available at www.balkanmedicaljournal.org

Tuncer AA, Narcı A, Dilek FH, Baskın Embleton D, Çetinkurşun S. Benign cystic mesothelioma in a child: case report and review of the literature.

Balkan Med J 2016;33:232-4 


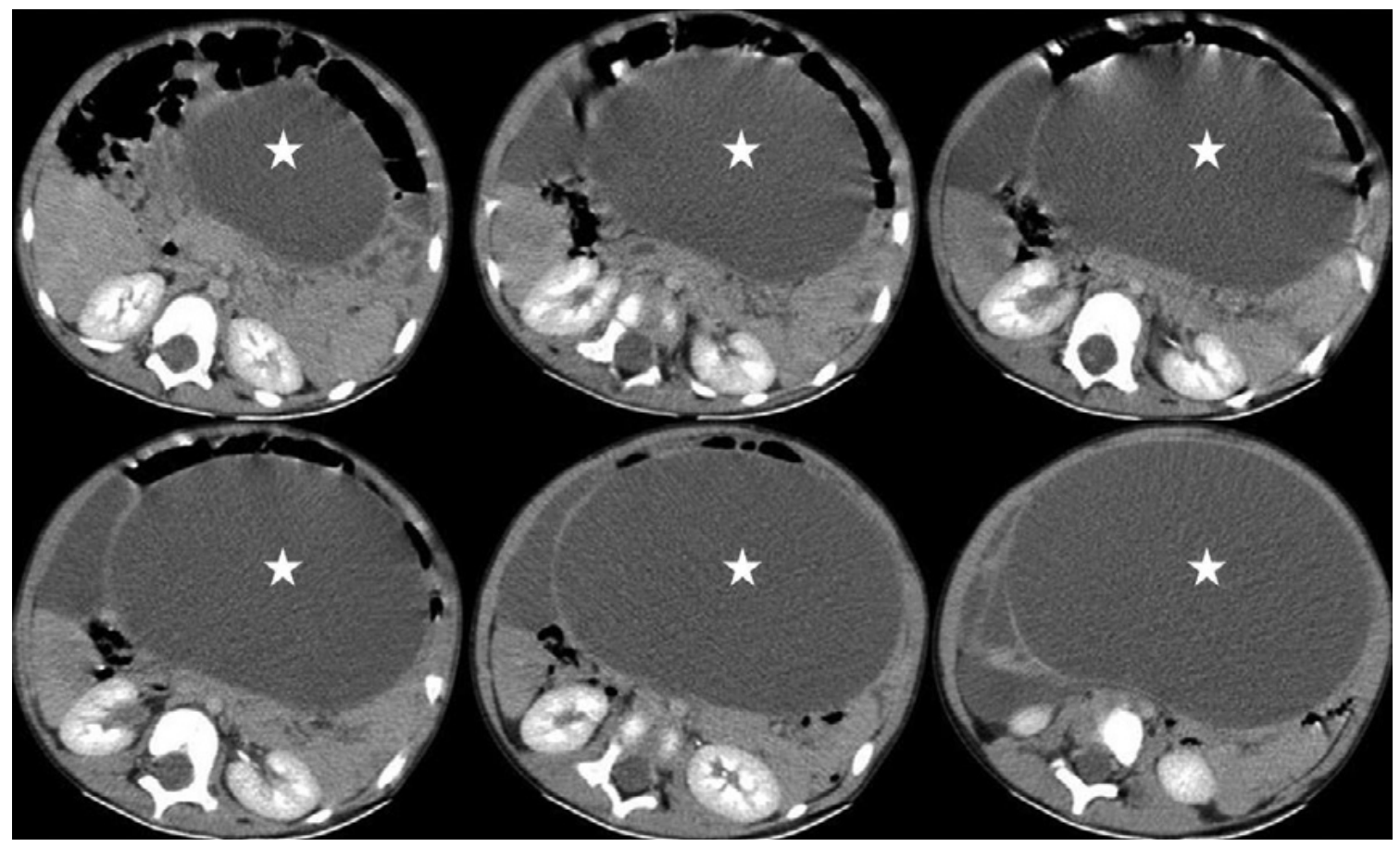

FIG. 1. Contrast-enhanced axial computed tomographic scan showed a $15 \times 13 \times 11 \mathrm{~cm}$ multicystic mass extending from bladder to liver with no solid components (asterisk).

These findings were pathognomonic for the BCM. The patient is doing well with no signs of recurrence 5 years after surgery.

\section{DISCUSSION}

Benign cystic mesothelioma is a rare abdominal tumor among women of reproductive age. It is also called an inflammatory inclusion cyst, benign cystic mesothelioma and multicystic mesothelial proliferation (2). Generally, it originates in the pelvic retroperitoneum. It may also originate in serosa of the pelvic viscera and spread to the visceral peritoneum of pelvic and abdominal organs (2). In addition, extra-abdominal localized cases such as the chest and pericardium have been reported $(3,4)$. The most common cause of admission to the hospital is pelvic and lower abdominal pain. A palpable mass can be determined in some cases, but the lesions can occasionally be incidentally encountered during laparotomy. An infrequent reason for ascites in childhood should be kept in mind (5). There is no consensus about the etiology of BCM, but neoplastic or inflammatory events have been hypothesized as a reason, as it correlates in reproductive age with pelvic inflammatory disease (6). Patients who have been diagnosed with Familial Mediterranean Fever have subsequently developed BCM or malignant mesothelioma (6). BCM is assumed to be a variant ranging in malign and benign mesothelioma (5). Exposure to asbestos is not considered a factor in BCM development. The lack of asbestos exposure in the patient's story supports the non-neoplastic nature of our patient. Progression to malignancy is rare, but it has been reported in 2 cases in the literature nevertheless (6). The probability of $\mathrm{BCM}$ recurrence can increase to $75 \%$ and has occurred in an early period such as 1 month or in a late period such as 16 years later (case reports in the literature) (7). The preoperative diagnosis of benign cystic mesothelioma is difficult because of the nonspecific imaging. Cellular analysis of peritoneal washings can be useful for diagnosis in the preoperative period in recent studies, but inflammatory changes are almost the same in some infections, cirrhosis and connective tissue disorders, meaning that this is not specific for diagnosis (8). The diagnosis is made with a combination of cytology of the peritoneal washing including abundant mesothelial cells, histology and clinical story differentiation from other cystic masses such as cystic lymphangioma and malignant mesothelioma (9). In our case, by histopathological examination of the specimen, definitive diagnosis was verified. Immunohistochemical studies revealed multiple cysts lined by mesothelial cells and there was strong cytoplasmic immunoreactivity for calretinin (Calretinin (SP 13); Lab Vision Corporation, Fremont, USA) in cells lining the cysts.

En block removal of BCM via laparotomy or laparoscopy is a frequently used technique, and was used in our patient. However, different treatment methods are used in adult patients, such as hormonal managements, laser ablation, chemotherapy and image-guided percutaneous drainage or sclerotherapy (8). Lim and colleagues used sclerotherapy (povidone-iodine (10\% 


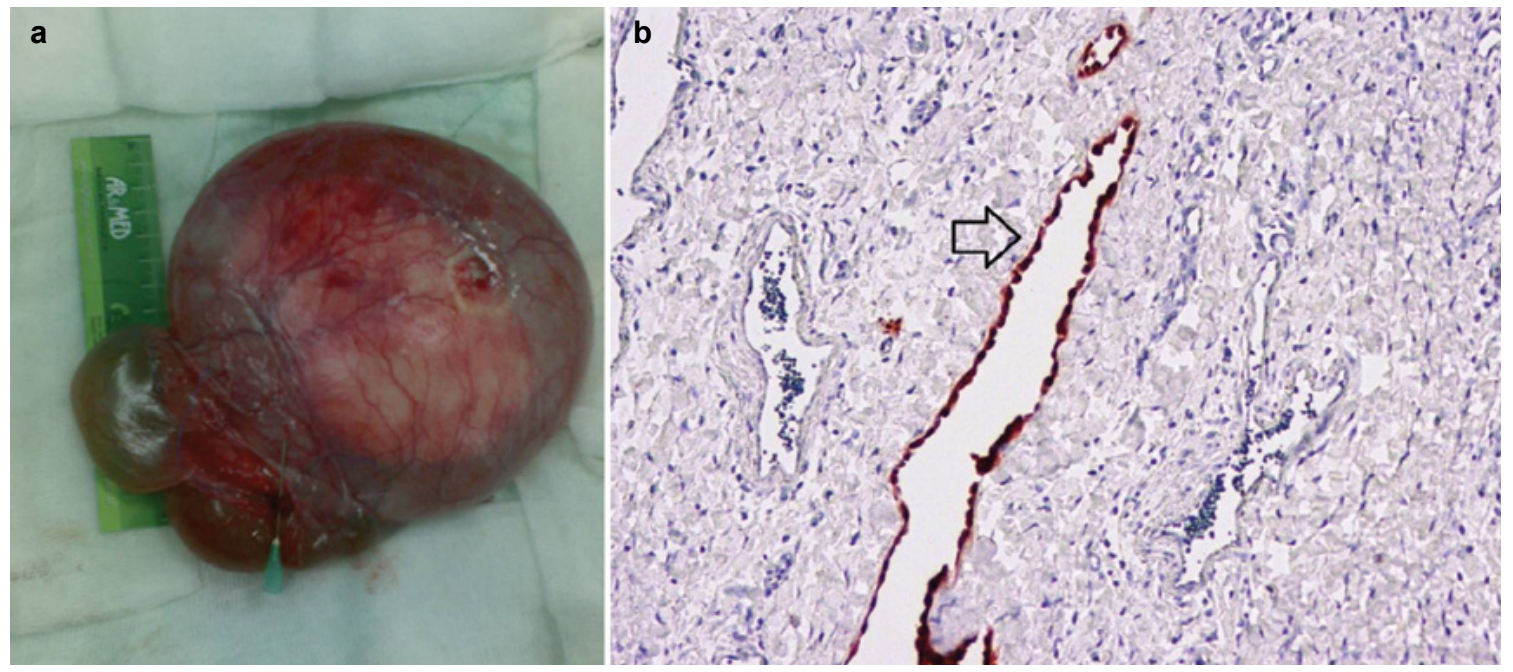

FIG. 2. a, b. Postoperative appearance of the mass. Sticking to the liver pedicle section, shown marked with injector needle (a). Strong cytoplasmic immunoreactivity for calretinin in cells lining the cysts. Calretinin staining in cells lining the cysts (arrowed) at higher magnification (x100) (b).

Povidone-iodine; SungKwang pharmaceuticals, Bucheon, Korea) and ethanol (Ethanol; J.T. Baker, Deventer, Holland)) for the treatment of BCM with a high success rate (10). Despite the variety of treatment options, there is no absolute consensus on treatment because the underlying pathogenesis, long-term results and complication rates are unknown. Contrary to our case, en block removal of mesothelioma is often not possible, recurrence is frequent and malignant degeneration has been reported; thus, accurate diagnosis requires histological evaluation of a specimen.

Benign cystic mesothelioma should be kept in mind as an unusual reason for an abdominal mass in children as it may lead to confused preoperative diagnosis. Although rare, patients should be followed throughout life because of the risk of recurrence and malignant degeneration.

\section{Ethics Committee Approval: N/A.}

Informed Consent: Written informed consent was obtained from the patient's parent who participated in this case.

Peer-review: Externally peer-reviewed.

Author contributions: Concept - A.A.T., S.Ç., A.N.; Design S.Ç., A.N., D.B.E.; Supervision - S.Ç., A.N., D.B.E.; Resource - S.Ç., A.A.T., F.H.D.; Materials - F.H.D., A.N., D.B.E.; Data Collection \&/ or Processing - A.A.T., D.B.E., A.N.; Analysis \&/or Interpretation - A.A.T., D.B.E., A.N., F.H.D.; Literature Search - A.A.T., D.B.E., S.Ç.; Writing - A.A.T., D.B.E., S.Ç.; Critical Reviews - D.B.E., A.A.T., S.Ç., A.N., F.H.D.

Conflict of Interest: No conflict of interest was declared by the authors.

Financial Disclosure: The authors declared that this study has received no financial support.

\section{REFERENCES}

1. Shakya VC, Agrawal CS, Karki S, Sah PL, Poudel P, Adhikary S. Benign cystic mesothelioma of the peritoneum in a child-case report and review of the literature. J Pediatr Surg 2011;46:23-6. [CrossRef]

2. Di Blasi A, Boscaino A, Dominicis GD, Marsilia GM, D'Antonio A, Nappi A. Multicystic mesothelioma of the liver with secondary involvement of peritoneum and inguinal region. Int J Surg Pathol 2004;12:87-91. [CrossRef]

3. Sawh RN, Malpica A, Deavers MT, Liu J, Silva EG. Benign cystic mesothelioma of the peritoneum: a clinicopathologic study of 17 cases and immunohistochemical analysis of estrogen and progesterone receptor status. Hum Pathol 2003;34:369-74. [CrossRef]

4. Drut R, Quijano G. Multilocular mesothelial inclusion cysts (socalled benign multicystic mesothelioma) of pericardium. Histopathology 1999;34:472-4. [CrossRef]

5. McCullagh M, Keen C, Dykes E. Cystic mesothelioma of the peritoneum: a rare cause of 'ascites' in children. J Pediatr Surg 1994;29:1205-7. [CrossRef]

6. Safioleas MC, Constantinos K, Michael S, Konstantinos G, Constantinos S, Alkividas K. Benign multicystic peritoneal mesothelioma: a case report and review of the literature. World $J$ Gastroenterol 2006;12:5739-42. [CrossRef]

7. Raafat F, Egan M. Benign cystic mesothelioma of the peritoneum: immunohistochemical and ultrastructural features in a child. Pediatr Pathol 1998;8:321-9. [CrossRef]

8. Vallerie AM, Lerner JP, Wright JD, Baxi LV. Peritoneal inclusion cysts: a review. Obstet Gynecol Surv 2009;64:321-34. [CrossRef]

9. Assaly M, Bongiovanni M, Kumar N, Egger JF, Pelte MF, Genevay $\mathrm{M}$, et al. Cytology of benign multicystic peritoneal mesothelioma in peritoneal washings. Cytopathology 2008;19:224-8. [CrossRef]

10. Lim HK, Cho JY, Kim SH. Sclerotherapy of peritoneal inclusion cysts: a long-term evaluation study. Abdom Imaging 2010;35:431-6. [CrossRef] 